\title{
Refractive Error in Nigerian Adults: Prevalence, Type, and Spectacle Coverage
}

\author{
Christian Ezelum, ${ }^{1}$ Hessom Razavi, ${ }^{2}$ Selvaraj Sivasubramaniam, ${ }^{3}$ Clare E. Gilbert, ${ }^{3}$ \\ Gudlavalleti V. S. Murtby, ${ }^{3}$ Gabriel Entekume, ${ }^{4}$ Tafida Abubakar, ${ }^{5}$ and \\ Nigeria National Blindness and Visual Impairment Study Group ${ }^{6}$
}

Purpose. To provide data on prevalence and types of refractive error and the spectacle-wearing rate among adults in Nigeria and the degree to which the need for distance correction could be met by off-the-shelf spectacles.

Methods. Multistage, stratified, cluster random sampling with probability proportional to size was used to identify a nationally representative sample of 15,027 persons aged $\geq 40$ years. Distance vision was measured using a reduced logMAR tumbling-E chart. All participants underwent autorefraction, and those with presenting acuity of $<6 / 12$ in one or both eyes had their corrected acuity measured and underwent detailed clinical examination to determine the cause.

RESULTS. Included in the survey were 13,599 (89.9\%) of the 15,122 persons aged $\geq 40$ years who were enumerated. Uncorrected refractive error was responsible for $77.9 \%$ of mild visual impairment $(<6 / 12-6 / 18), 57.1 \%$ of moderate visual impairment $(<6 / 18-6 / 60), 11.3 \%$ of severe visual impairment $(<6 /$ $60-3 / 60)$, and $1.4 \%$ of blindness $(<3 / 60)$. The crude prevalence of myopia $(\leq 0.5 \mathrm{D})$ and high myopia $(\leq 5.0 \mathrm{D})$ were $16.2 \%$ and $2.1 \%$, respectively. Spectacles could improve the vision of $1279(9.4 \%)$ and $882(6.5 \%)$ participants at the $6 / 12$ and $6 / 18$ level, respectively, but only $3.4 \%$ and $4.4 \%$ of these individuals wore spectacles to the examination site. Approximately 2,140,000 adults in Nigeria would benefit from spectacles that improved their vision from $<6 / 12$ to $\geq 6 / 12$. More than a third of the need could be met by low-cost, off-the-shelf spectacles.

Conclusions. Uncorrected refractive errors are an important cause of visual impairment in Nigeria, and services must be dramatically improved to meet the need. (Invest Ophthalmol Vis Sci. 2011;52:5449-5456) DOI:10.1167/iovs.10-6770

From the ${ }^{1}$ Ministry of Health, Awka, Anambra State, Nigeria; the ${ }^{2}$ Royal Perth Hospital, Perth, Western Australia, Australia; the ${ }^{3}$ International Centre for Eye Health, London School of Hygiene and Tropical Medicine, London, United Kingdom; the ${ }^{4}$ Vision Health Services, Ikeja Lagos State, Nigeria; the ${ }^{5}$ Ministry of Health, Dutse, Jigawa State, Nigeria.

${ }^{6}$ Additional members of the Nigeria National Blindness and Visual Impairment Study Group are listed in the Appendix.

Supported by Sightsavers International, Christian Blind Mission (CBM), and Vellux Stiftung.

Submitted for publication October 22, 2010; revised January 5 2011; accepted January 21, 2011.

Disclosure: C. Ezelum, None; H. Razavi, None; S. Sivasubramaniam, None; C.E. Gilbert, None; G.V.S. Murthy, None; G. Entekume, None; T. Abubakar, None

Corresponding author: Gudlavalleti V. S. Murthy, International Centre for Eye Health, London School of Hygiene and Tropical Medicine, Keppel Street, London-WC1E7HT, UK; gvs.murthy@lshtm.ac.uk.
$\mathbf{R}$ efractive error (RE) is a priority for the global VISION2020: The Right to Sight initiative. ${ }^{1}$ Worldwide, uncorrected RE is the main cause of moderate and severe visual impairment (VI) and the second leading cause of blindness, accounting for an estimated 153 million and 8 million affected persons, respectively, despite the fact that correction of RE with appropriate spectacles is one of the most cost-effective interventions in eye health. ${ }^{2}$

$\mathrm{RE}$ is a significant cause of low vision in African countries, but available data are limited. ${ }^{3}$ Nigeria is the most populous country in Africa. ${ }^{4}$ Small, population-based studies in Nigeria have shown uncorrected RE, along with cataract and glaucoma, to be among the leading causes of blindness, ${ }^{5-7}$ VI, and low vision. ${ }^{8-12}$ Hospital- or industry-based Nigerian studies have shown RE to be the commonest ocular condition, ${ }^{13-15} \mathrm{a}$ leading cause of VI, ${ }^{16-20}$ and associated with increased absenteeism and reduced productivity. ${ }^{14}$ However, these studies were not nationally representative and cannot be extrapolated to the entire country due to their limited geographic scope, small sample sizes, and lack of validated methodology.

$\mathrm{RE}$ is a complex and multifactorial condition that varies in prevalence across populations with different genetics, demographics, ocular, and extrinsic factors, such as education. ${ }^{21}$ The Nigerian National Blindness and VI Survey ${ }^{22-24}$ indicated that uncorrected RE accounts for $57.1 \%$ of moderate VI (visual acuity [VA], >6/18-6/60). Economic consequences are likely to be considerable, as uncorrected RE affects people in the working-age group. To our knowledge, no national survey of $\mathrm{RE}$ has been undertaken in Africa, whereas some have been undertaken in Asia. ${ }^{25-27}$ This article reports data on the prevalence and types of RE among adults aged 40 or more years in Nigeria.

\section{Methods}

The Nigeria survey was conducted over 30 months from 2005 to 2007 The methods have been described in detail elsewhere, ${ }^{24}$ and therefore we include only the pertinent elements here.

\section{Definitions}

Refractive Error. The WHO categories of VI were used. Blindness was defined as a presenting VA of $<3 / 60(<20 / 400$, logMAR $>1.30$ ) in the better eye, severe visual impairment (SVI) as VA $<6 / 60$ to $3 / 60$, and moderate visual impairment (MVI) as $<6 / 18$ to $6 / 60$. We also used the term "near normal" to describe VA of $<6 / 12(<20 / 40$, $\log$ MAR $>0.3$ ), but $\geq 6 / 18$ in the better eye. Spherical equivalent (SE) was calculated as half the cylinder plus the spherical component. Low myopia was defined as SE worse than $-0.5 \mathrm{D}$ (i.e., $<-0.5 \mathrm{D}$ ), but better than or equal to $-5 \mathrm{D}$ (i.e., $\geq-5 \mathrm{D}$ ), and high myopia as SE worse than $-5 \mathrm{D}$ (i.e., $<-5 \mathrm{D}$ ). Low hypermetropia was defined as SE worse than $+0.5 \mathrm{D}$ (i.e., $\geq+0.5 \mathrm{D}$ ), but better than or equal to $+5 \mathrm{D}$ (i.e., $\leq+5 \mathrm{D}$ ), and high hypermetropia as worse than $+5 \mathrm{D}$ (i.e., $>5$ 
D). Astigmatism (minus cylinder format) was defined as a cylindrical error worse than $0.75 \mathrm{D}$ (Table 1 ).

Improvers. Participants whose unaided VA was $<6 / 12$ in the better eye but subsequently improved by one or more visual categories, either with their spectacles or with best correction, were labeled "improvers."

Need for Spectacles. The need for spectacles among the improvers could either have been "met" or "unmet." So as to be comparable with other surveys, "met need" describes the number of participants who wore distance spectacles and had VA $<6 / 12$ in the better eye without correction, but who achieved $6 / 12$ or better in the better eye with their present distance spectacles. "Unmet need" was defined as the number of participants who did not wear spectacles and who had VA $<6 / 12$ in the better eye without correction, but who could achieve $\geq 6 / 12$ in the better eye with correction. Met need and unmet needs were also calculated with a cutoff of $<6 / 18$ in the better eye.

Some participants presented for VA measurement wearing spectacles, but with an incorrect prescription, defined as a presenting VA of $<6 / 12$ (or $<6 / 18$ ), which improved by one or more VA categories with best correction. If best correction improved their VA to $\geq 6 / 12$ (or $\geq 6 / 18$ ) they were defined as having unmet need at the relevant cutoff.

Spectacle Coverage. The percentage of spectacle coverage was defined as: met need/total need $\times 100 \%$, where total need is met need + unmet need.

\section{Sampling Design and Sample Size}

The sample size necessary to meet the parameters of the study was calculated as 15,375 persons aged 40 years or above. Multistage, stratified, cluster random sampling, with probability proportional to size was used to identify a nationally representative sample. Stratification was by place of usual residence (urban/rural). A cluster size of 50 eligible adults was used in randomly selecting a total of 310 clusters across the country, of which 226 (72.9\%) were rural and $84(27.1 \%)$ were urban. Five clusters had to be abandoned due to civil unrest or refusal to participate.

\section{Sampling Process, Enumeration, and Registration}

Enumerated respondents were invited to attend the "temporary clinical station" set up in each cluster. Eligible respondents were registered with a unique identification number, after verifying their age and residency status, and recording information on sex, ethnic group, occupational status, religion, educational attainment, water supply, and household sanitation.

\section{Visual Acuity Measurement}

Visual acuity was measured by an ophthalmic nurse at the central examination site, using a reduced log MAR tumbling-E chart to take three separate measurements. This chart has been validated for use in surveys. ${ }^{28}$ First, unaided VA of each eye was measured at $4 \mathrm{~m}$ (even if they habitually used distance spectacles), followed by a second assessment of both eyes together (unaided VA). Those who had distance glasses were then reassessed wearing their available glasses (presenting vision). Participants with VA $\leq 6 / 12$ in one or both eyes underwent extensive examination, including dilated funduscopy.

\section{Refractokeratometry}

All participants had noncycloplegic refraction by an optometrist using an autorefractokeratometer (ARKM-100; Takagi Seiko, Japan) that was regularly calibrated. If automated readings could not be obtained, refraction was done manually. Participants with VA $<6 / 12$ in one or both eyes had their corrected VA measured by subjective refraction based on autorefraction readings. This method was used to estimate the contribution of RE to a participant's VI. VI due to significant RE and uncorrected aphakia was defined as acuity of $<6 / 18$ in the better eye before refraction improving to $\geq 6 / 18$ in one or both eyes after refraction.



Downloaded From: http://iovs.arvojournals.org/pdfaccess.ashx?url=/data/journals/iovs/933462/ on 10/19/2017 


\section{Eye Examination}

Participants had an initial anterior segment examination using a torch, including grading lens opacities (LO) against the red reflex, using the Mehra-Minassian (MM) system. ${ }^{29}$ Information on the location and type of cataract surgery was elicited, as well as on the use of aphakic correction. Participants proceeded to a more detailed examination by a clinical ophthalmologist if they met certain criteria, including presenting VA $<6 / 12$ in one or both eyes. For these participants, the ophthalmologists determined the cause(s) of visual loss by using the principles outlined in the WHO Prevention of Blindness Performa (Version III). ${ }^{30}$ All participants with VI were referred to the nearest eye facility.

A detailed examination was performed with a slit lamp microscope (SL 115 Classic Slit Lamp; Carl Zeiss Meditec AG, Jena, Germany), 81-D aspheric condensing lens (Volk Optical, Mentor, OH), Goldmann applanation tonometer, a two-mirror lens (Volk) with no flange for gonioscopy, and a digital camera (Visucam Lite Desktop Fundus Camera; Carl Zeiss Meditec AG).

\section{Approvals}

The study adhered to the tenets of the Declaration of Helsinki and was approved by Ethics Committee of London School of Hygiene and Tropical Medicine and Nigeria's Federal Ministry of Health. Informed consent was obtained from the head of the household and all adult respondents

\section{Statistical Analysis}

There was a high correlation between right and left eyes (Pearson's correlation $0.72 ; P=0.001$ ), and therefore, data are reported only for right eyes. All those with no recorded autorefraction results and those who were pseudo/aphakic in their right eyes were excluded. To ascertain effects of LO on RE, a further analysis excluded participants with significant $\mathrm{LO}$, defined as grade $2 \mathrm{~B}$ or more (MM grading). ${ }^{29}$ The odds ratio (presented with the $95 \%$ confidence interval) was used in univariate analysis of spectacle use with key variables, such as sex, literacy, education, occupation, and location of residence.

The following analyses were undertaken to determine proportion of individuals with significant RE who could potentially benefit from off-the-shelf spectacles. Individuals with presenting VA $<6 / 12$ in the better eye but improving to $6 / 12$ or better were identified first. Individuals who had undergone procedures for cataract in both eyes (cataract surgery with/or without IOL, or couching) were then excluded. The following criteria were explored for suitability for off-theshelf spectacles (1) anisometropia of $\leq 1.0$ D SE with $\leq 1.0$ D astigmatism in both eyes; (2) anisometropia of $\leq 1.5 \mathrm{D}$ SE with $\leq 1.5 \mathrm{D}$ astigmatism in both eyes; and (3) anisometropia of $\leq 2.0 \mathrm{D}$ SE with $\leq 1.25 \mathrm{D}$ astigmatism in both eyes. ${ }^{26}$

Data were analyzed (Stata 11.0; Stata Corp, College Station, TX), and prevalence estimates with $95 \%$ confidence intervals and OR from the regression analyses are presented. All analyses took account of additional variation due to stratified cluster sampling design. The design effect due to cluster sampling was taken into account in the calculation of confidence intervals and odd ratios in the regression analysis using the generalized estimating equation (GEE). The Wald $F$-test was used to assess the interaction effect in the multiple regression analyses. Variables with $P<0.2$ in univariate analyses were included in the multivariate models. $P<0.05$ was considered to be statistically significant.

\section{Results}

\section{Demographics}

A total of 15,122 eligible adults aged 40 years and older were enumerated, 13,599 of whom were examined (89.9\% response rate, which was similar across all geopolitical zones). The age and sex of those enumerated and those examined were similar, but younger men ( $40-49$ years) were underrepresented (Pearson $R=-3.94 ; P<0.001)$.
Of the 13,599 participants examined, eight had no VA data, and $890(6.5 \%)$ had no information on RE because of ocular factors including corneal opacity, phthisis, and inability to undergo refraction because of blindness. A further 299 (2.2\%) participants who had undergone cataract surgery were excluded, leaving 12,402 participants for analysis. Some analyses also excluded 1,715 participants with significant LO, leaving 10,687 participants for analysis.

\section{Distribution and Prevalence of Refractive Error}

The distribution of SE refractive error for right eyes was leptokurtotic (Fig. 1). The overall mean and median SE were $+0.36 \mathrm{D}$ (95\% CI, 0.32- 0.41) and +0.63 D (IQR -0.13, 1.25), respectively. After excluding participants with significant LO, these were $+0.67 \mathrm{D}(0.63,0.70)$ and $+0.63 \mathrm{D}$ (IQR: 0.13 , 1.38), respectively (Fig. 1).

Myopia. The crude prevalences of myopia $(<-0.5 \mathrm{D})$ and high myopia $(<-5.0 \mathrm{D})$ were $16.2 \%(n=2003 ; 95 \% \mathrm{CI}$, $15.2-17.1)$ and $2.1 \%(n=259 ; 95 \% \mathrm{CI}, 1.8-2.4)$, respectively (Table 1). After excluding participants with significant lens opacities, the crude prevalence of myopia was $9.4 \%$ (95\% CI, $8.7 \%-10.2 \%)$ and of high myopia $0.7 \%$ (95\% CI, $0.5-0.9 \%)$. The men had a significantly higher prevalence of myopia $(16.9 \%$ versus $15.5 \%$; OR $1.29,95 \% \mathrm{CI}, 1.14-1.47$ ). The prevalence of myopia increased steadily with increasing age $(P<0.001$; Fig. 2).

Hypermetropia. The crude prevalence of hypermetropia $(>+0.5 \mathrm{D})$ was $50.7 \%(n=6283$; 95\% CI, 49.5-51.9), showing an inverse J-shaped distribution with age (Fig. 2). Excluding those with significant LO did not significantly affect prevalence of hypermetropia (52.1\%; 95\% CI, 50.8-53.3). Prevalence of high hypermetropia was $0.5 \%(0.4 \%-0.6 \%)$. The women had a significantly higher prevalence of hypermetropia ( $55.6 \%$ versus $44.7 \%$, OR 1.55 ; 95\% CI, $1.43-1.68$ )

Astigmatism. The crude prevalence of astigmatism was $63.0 \%$ (95\% CI, 61.8 - 64.1), which decreased to 58.7\% (95\% CI, 57.5-59.9) after those with visually disabling lens opacity were excluded. Prevalence increased significantly with age $(P=$ 0.001). After adjusting for age, the prevalence of myopia was $14.1 \%$ and of hypermetropia was $51.1 \%$, which changed to 9.7\% and 55\%, respectively, when LO were excluded (Table 2).

\section{Sex, Literacy, Residence, and Occupation}

Univariate analysis showed that the men had a greater risk of myopia (OR 1.29, 95\% CI, 1.14-1.47), but a lower risk of hypermetropia (OR 0.61, 95\% CI, 0.55-0.66) than did women.



Figure 1. Refractive error in phakic participants, after excluding those with significant lens opacities. 


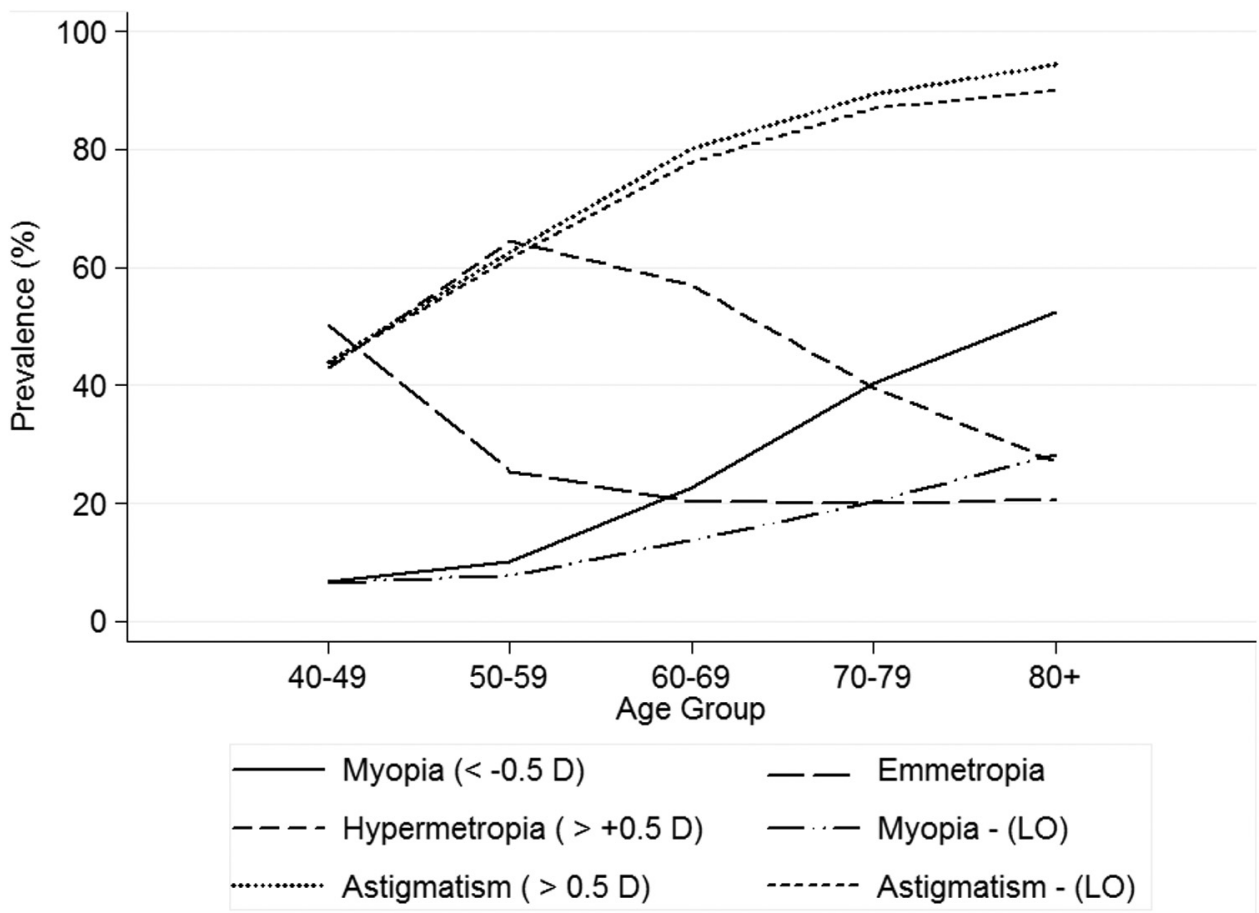

Figure 2. Crude prevalence of refractive errors and in a subgroup of participants without significant lens opacities. (-)LO, lens opacities (cataract) excluded.
Illiteracy was associated with myopia (OR 1.37, 95\% CI, 1.191.58), hypermetropia (OR $1.35,95 \% \mathrm{CI}, 1.23-1.48$ ), and astigmatism (OR 1.57, 95\% CI, 1.44-1.72). Residence in a rural area was associated with an increased risk of myopia (OR 1.35, 95\% CI, 1.11-1.63) and astigmatism (OR 1.21, 95\% CI, 1.08-1.35). Manual occupation was also associated with myopia (OR 1.57 , 95\% CI, 1.35-1.84) and astigmatism (OR 1.50, 95\% CI, 1.381.63; Table 3; Fig. 3).

\section{Spectacle Wear}

Only $1.2 \%$ (169) of phakic participants (1.2\%) wore distance spectacles to the examination site. Another 38 claimed to own distance spectacles, but did not habitually wear them and were classified as nonwearers. Of the 2003 adults identified as having myopia, only $28(1.4 \%)$ were wearing spectacles, and none of those had high myopia $(n=258)$. Of the 6823 participants identified with hypermetropia, 79 (1.3\%) were wearing spectacles. The prevalence of spectacle wear increased with age (0.69\% in $40-49$-year-olds, $0.97 \%$ in $50-59$-year-olds, $1.22 \%$ in 60 -69-year-olds, and 70-79-year-olds, and $1.47 \%$ in $>80$-yearolds). The 299 participants who had undergone cataract sur-

TABle 2. Age-Adjusted Prevalence of Different Refractive Errors among Nigerian Adults

\begin{tabular}{lccr}
\hline & & \multicolumn{2}{c}{ Prevalence (\%) } \\
\cline { 3 - 4 } Refractive Error & $\boldsymbol{N}$ & Crude & Adjusted \\
\hline Myopia & 12,402 & 16.2 & 14.1 \\
Emmetropia & 12,402 & 33.2 & 34.8 \\
Hypermetropia & 12,402 & 50.7 & 51.1 \\
Myopia LO & 10,687 & 9.4 & 9.7 \\
Emmetropia LO & 10,687 & 35.5 & 35.3 \\
Hypermetropia LO & 10,687 & 55.1 & 55.0 \\
Astigmatism & 12,402 & 63.0 & 60.3 \\
Astigmatism LO & 10,687 & 58.7 & 59.2 \\
\hline
\end{tabular}

(-)LO, excluding lens opacities (cataract). gery were also more likely to be wearing spectacles $(14.4 \%$ versus $0.9 \%$ in phakic participants).

\section{Improvers and Incorrect Prescriptions}

A total of 2248 (16.5\%; 95\% CI, 15.7-17.4) participants were improvers. We estimate that 3,890,000 (95\% CI, 3,700,000 $4,100,000)$ adults over 40 years of age would require optical correction to improve VA status by at least one vision category. Just over half ( $n=80,51.0 \%$ ) of the spectacle wearers had an incorrect prescription at the $6 / 12$ cutoff; this number was lower at the $6 / 18$ cutoff $(n=65,41.4 \%)$.

\section{Spectacle Coverage}

A need for spectacles was identified in 1279 (9.4\%) and 882 (6.5\%) individuals at the $6 / 12$ and $6 / 18$ cutoffs, respectively, only 43 and 39 of whom were wearing appropriate spectacles. The overall spectacle coverage was 3.4\% (95\% CI, 2.3-4.4) and $4.4 \%(95 \%$ CI, 2.9-5.9) at the $6 / 12$ and $6 / 18$ cutoffs, respectively.

There were 1190 individuals with significant RE at the 6/12 level who were phakic in one or both eyes (Table 4). The proportion of the need that could be met by off-the-shelf spectacles, using different criteria for anisometropia and astigmatism, ranged from $33.9 \%$ to $44.4 \%$ (Table 4 ).

\section{Unmet Need}

Over 90\% (OR 96.6\%, 95\% CI, 95.5-97.7) of participants who needed spectacles did not own them, owned a pair but did not use them routinely, or used an incorrect prescription. Our results show that $9.1 \%$ (95\% CI: 8.5-9.6) of all Nigerian adults over 40 years $(2,140,000$ individuals), have an unmet need for spectacles, which would improve their distance vision from $<6 / 12$ to $\geq 6 / 12$.

\section{Discussion}

This survey provides the first population-based data on the magnitude of RE in Nigeria. The two main findings are the 
TABLE 3. Association of Different REs with Sociodemographic Factors, Excluding Lens Opacities

\begin{tabular}{|c|c|c|c|c|c|c|c|c|c|c|}
\hline \multirow[b]{2}{*}{ Variables } & \multirow[b]{2}{*}{$N$} & \multicolumn{3}{|c|}{ Myopia } & \multicolumn{3}{|c|}{ Hyperopia } & \multicolumn{3}{|c|}{ Astigmatism } \\
\hline & & $n$ & $\begin{array}{c}\text { Univariate } \\
\text { Analysis OR } \\
(95 \% \mathrm{CI})\end{array}$ & $\begin{array}{c}\text { Multivariate } \\
\text { Analysis OR } \\
(95 \% \mathrm{CI})\end{array}$ & $n$ & $\begin{array}{c}\text { Univariate } \\
\text { Analysis OR } \\
(95 \% \mathrm{CI})\end{array}$ & $\begin{array}{c}\text { Multivariate } \\
\text { Analysis OR } \\
(95 \% \mathrm{CI})\end{array}$ & $n$ & $\begin{array}{c}\text { Univariate } \\
\text { Analysis OR } \\
(95 \% \mathrm{CI})\end{array}$ & $\begin{array}{c}\text { Multivariate } \\
\text { Analysis OR } \\
(95 \% \mathrm{CI})\end{array}$ \\
\hline \multicolumn{11}{|l|}{ Age group } \\
\hline $40-49$ & 4717 & 310 & 1.0 & 1.0 & 2030 & 1.0 & 1.0 & 2060 & 1.0 & 1.0 \\
\hline $50-59$ & 3192 & 248 & $1.2(1.0-1.4)$ & $1.1(1.0-1.4)$ & 2126 & $2.6(2.4-2.9)$ & $2.8(2.5-3.0)$ & 1966 & $2.1(1.9-2.3)$ & $2.0(1.8-2.2)$ \\
\hline $60-69$ & 1907 & 262 & $2.3(1.9-2.7)$ & $2.1(1.7-2.5)$ & 1246 & $2.5(2.2-2.8)$ & $2.6(2.4-3.0)$ & 1485 & $4.5(4.0-5.2)$ & $4.2(3.7-4.9)$ \\
\hline $70-79$ & 712 & 144 & $3.6(2.9-4.5)$ & $3.1(2.5-3.9)$ & 403 & $1.7(1.5-2.0)$ & $1.9(1.6-2.2)$ & 619 & $8.6(6.8-10.8)$ & $7.7(6.1-9.7)$ \\
\hline $80+$ & 159 & 45 & $5.6(3.8-8.3)$ & $4.6(3.1-6.8)$ & 78 & $1.3(0.9-1.8)$ & $1.5(1.1-2.1)$ & 143 & $11.5(6.9-20.2)$ & $10.0(6.0-16.6)$ \\
\hline \multicolumn{11}{|c|}{$10.3(0.30 .4)$} \\
\hline Female & 5728 & 482 & 1.0 & 1.0 & 3479 & 1.0 & 1.0 & 3316 & 1.0 & \\
\hline Male & 4959 & 527 & $1.3(1.1-1.5)$ & $1.2(1.1-1.5)$ & 2404 & $0.6(0.6-0.7)$ & $0.6(0.5-0.6)$ & 2957 & $1.1(1.0-1.2)$ & \\
\hline \multicolumn{11}{|l|}{ Literacy } \\
\hline Literate & 5150 & 415 & 1.0 & 1.0 & 2636 & 1.0 & & 2731 & 1.0 & 1.0 \\
\hline Illiterate & 5537 & 594 & $1.4(1.2-1.6)$ & $1.2(1.0-1.4)$ & 3247 & $1.3(1.2-1.5)$ & & 3542 & $1.6(1.4-1.7)$ & $1.2(1.1-1.3)$ \\
\hline \multicolumn{11}{|l|}{ Residence } \\
\hline Urban & 2407 & 183 & 1.0 & & 1363 & 1.0 & & 1327 & 1.0 & \\
\hline Rural & 8280 & 826 & $1.3(1.1-1.6)$ & & 4520 & $0.9(0.8-1.0)$ & & 4946 & $1.2(1.1-1.3)$ & \\
\hline \multicolumn{11}{|l|}{ Occupation } \\
\hline Nonmanual & 4645 & 339 & 1.0 & 1.0 & 2555 & 1.0 & & 2463 & 1.0 & 1.0 \\
\hline Manual & 5884 & 649 & $1.6(1.3-1.8)$ & $1.2(1.1-1.5)$ & 3234 & $1.0(0.9-1.1)$ & & 3699 & $1.5(1.4-1.6)$ & $1.2(1.1-1.3)$ \\
\hline Other & 157 & 21 & $2.0(1.2-3.2)$ & $1.2(0.7-2.1)$ & 93 & $1.2(0.7-2.1)$ & & 110 & $2.1(1.4-3.0)$ & $1.1(0.8-1.7)$ \\
\hline
\end{tabular}

relatively low prevalence of myopia and the extremely low spectacle coverage. Data from studies undertaken in Asia, Europe, the Americas, and Australia are shown in Table 5 for comparison. The table contains only studies of adults conducted since 1985 that measured RE with reproducible methods.

Using autorefraction results and a VA cutoff of $<6 / 12$, we estimate that there are 15,765,000 (95\% CI, 15,530,000$16,001,000)$ adults with RE in Nigeria. Optical correction can potentially improve the vision of 4 million adults by one or more VA categories, and more than 2 million to normal levels of vision. Many of the remaining 2 million may require other interventions (i.e., cataract surgery).

The crude prevalence of myopia in Nigeria (16.2\%) was lower than that in Asia (Pakistan, Bangladesh, India, Singapore, and Myanmar), ${ }^{25,26,31-33}$ but comparable to Western populations (Netherlands, United States, and Australia) ${ }^{34,35,37}$ and similar to the adult black population in Barbados (21.9\%) (Table 5). ${ }^{39}$ The prevalence of high myopia (2.1\%) was similar to the rate in white Australians aged 40 years and older, ${ }^{37}$ higher

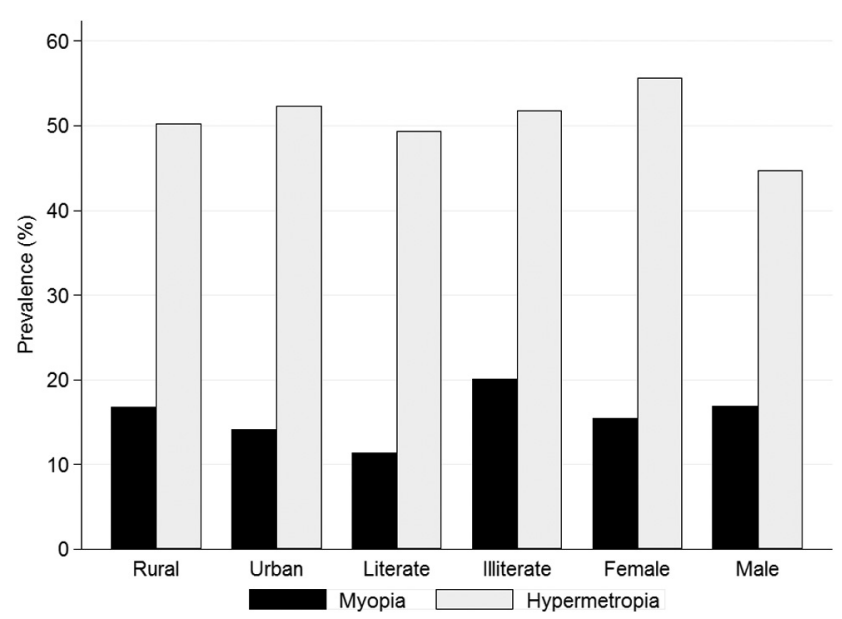

Figure 3. Prevalence of refractive error by place of residence, literacy, and sex. than findings in the Baltimore Eye Study (1.4\% overall) ${ }^{35}$ and in a study in Bangladesh (1.8\%). ${ }^{26}$ It is likely that these population differences are partly accounted for by a genetic mechanism for myopia, as demonstrated in multiple familial, familial aggregation, and twin studies that suggest the involvement of multiple genes rather than a single major gene effect. ${ }^{40}$ More data on the genetic basis of RE are needed from African populations.

The prevalence of myopia showed a steady increase with age, similar to reports from Pakistan ${ }^{25}$ and Bangladesh. ${ }^{26}$ Much of the myopia in older age groups was the result of cataract, and participants with significant LO accounted for $41.5 \%$ of all myopes. Effect of age on prevalence of myopia has been observed in other studies. ${ }^{25,26,31-39,41-46}$ However, this agerelated trend was evident, even after participants with visually significant cataract were excluded. In contrast, most studies of Western populations show a decrease in prevalence of myopia with age, followed by an increase at older ages (J-shaped relationship). ${ }^{39}$ There may be a U-shaped trend in Nigeria, with the decrease and subsequent increase in prevalence coming at earlier ages than Western populations. It would be instructive for future research in Nigeria to include refractive error in younger age groups as well, to elucidate the longitudinal changes and cohort effects that have been observed in other studies. ${ }^{42-45}$ The men in our survey had a slightly higher prevalence of myopia than did the women, as has been reported in other studies. ${ }^{26,37,47-49}$

The prevalence of hypermetropia (50.7\%) was considerably higher than that in most Asian studies, being closer to that in populations of predominantly European or African descent. The relationship between hypermetropia and age showed a pattern similar that in to studies from Asia and Barbados, ${ }^{25-27,31,33,39,49}$ with a rise to maximum levels in the 50- to 59-year-old group, followed by a decline in later years. Hypermetropia prevalence was significantly higher in women $(55.6 \%$ versus $44.7 \%)$, which has been observed elsewhere. ${ }^{26,31,37,39,50}$

Astigmatism was prevalent in $63.0 \%$ (58.7\%, after excluding those with visually significant cataract). Many studies of RE have not examined the prevalence of astigmatism. The prevalence in our survey was similar to findings from South India 
TABLE 4. Proportion of Need for Spectacle Correction at the 6/12 Level That Could Be Met by Off-theShelf Spectacles, Using Different Criteria for Anisometropia and Astigmatism

\begin{tabular}{|c|c|c|c|c|c|c|c|c|c|}
\hline \multirow[b]{2}{*}{ Age Group } & \multicolumn{3}{|c|}{$\leq 1 D$ SE and S1D cyl } & \multicolumn{3}{|c|}{$\leq 1.5 \mathrm{DSE}$ and $\leq 1.5 \mathrm{D}$ cyl } & \multicolumn{3}{|c|}{$\begin{array}{c}\leq 2 \mathrm{D} \text { SE } \underset{\text { cyl }}{\text { and }} \leq 1.25 \mathrm{D} \\
\text {. }\end{array}$} \\
\hline & $n$ & $\leq 1 \mathrm{D}$ & $\%$ & $n$ & $\leq 1.5 \mathrm{D}$ & $\%$ & $n$ & $\leq 2 \mathrm{D}$ & $\%$ \\
\hline $40-49$ years & 138 & 43 & 31.2 & 138 & 31 & 22.5 & 138 & 46 & 33.3 \\
\hline $50-59$ years & 278 & 105 & 37.8 & 278 & 88 & 31.7 & 278 & 114 & 41.0 \\
\hline $60-69$ years & 393 & 170 & 43.3 & 393 & 139 & 35.4 & 393 & 172 & 43.8 \\
\hline $70-79$ years & 285 & 111 & 39.0 & 285 & 100 & 35.1 & 285 & 133 & 46.7 \\
\hline $80+$ years & 96 & 37 & 38.5 & 96 & 45 & 46.9 & 96 & 63 & 65.6 \\
\hline Total & 1190 & 466 & 39.2 & 1190 & 403 & 33.9 & 1190 & 528 & 44.4 \\
\hline
\end{tabular}

Criteria were anisometropia (SE) and astigmatism in one or both eyes.

(60.4\% and $59.1 \%$ in rural and urban participants in Tamilnadu, respectively). ${ }^{49}$

Participants who were illiterate were more likely to be myopic or hypermetropic and to have astigmatism. Participants with manual occupations and those living in rural areas were also more likely to be myopic and have astigmatism. Some of these findings contrast with other populationbased studies, which have shown associations between myopia, higher education levels, professional occupations and residence in urban areas ${ }^{25,26,32,33,40,43,46,48,51}$ (in support of the use-abuse theory of myopia). There are, however, exceptions to these trends: The Baltimore Eye Study showed that the association between years of education and myopia was stronger for white persons than for black persons, ${ }^{35}$ the Chennai Study (India) showed a higher prevalence of myopia in participants living in rural areas, ${ }^{49}$ and the Bangladesh study showed a significantly lower risk of myopia with literacy, urban living, and nonmanual occupation. ${ }^{26}$ This variability in findings suggests that the risk factors for myopia are context specific, and that time spent outdoors may be the more important environmental variable in myopia in some populations. ${ }^{52}$

The leptokurtosis and negative skewness of the distribution of spherical equivalent RE in this population was similar to that in other studies. ${ }^{25,26,31-33,40,50,53}$ After participants with significant LO were excluded, the mean spherical equivalent was $+0.67 \mathrm{D}$, the same as Australians aged $\geq 49$ years, ${ }^{54}$ but different from adults aged $\geq 40$ years in Bangladesh $(-0.19 \mathrm{D}),{ }^{26}$ Pakistan $(-0.4 \mathrm{D}),{ }^{25}$ and Myanmar $(-1.3 \mathrm{D}) .{ }^{32}$
Spectacle coverage rates were significantly lower than reported among similar age groups in Bangladesh (3.0\%), ${ }^{27}$ Pakistan $(6.2 \%),{ }^{25}$ and India $(17.4 \%),{ }^{31}$ although it should be appreciated that the definition of "unmet need" for spectacles does not necessarily equate with demand for correction. None of the participants with high myopia were wearing spectacles. Incorrect prescriptions were common among the few wearing spectacles, with just over half improving by $\geq 1$ VA category with best correction. This suggests a need to improve both quality and affordability of optical and refractive services in Nigeria. Over one third of the need for distance correction among individuals who were phakic in one or both eyes could be met by off-the-shelf spectacles.

Limitations of this study include possible overestimation of myopia in younger participants, as autorefraction was not performed after cycloplegia. The analysis used refractive data from the right eye, which is in keeping with several other studies, ${ }^{26,32,33}$ but differs from some studies that included the worse eye in their analyses. 25,45,49 Younger males were underrepresented, as they were more likely to be at work at the time of examination, which may have led to a slight overestimation of refractive error. The MM lensgrading system was used to provide some data on lens opacities in all participants, regardless of their visual acuity. Individuals undergoing full ophthalmic examination had their lenses graded using LOCS III. ${ }^{55,56}$ finally, presbyopia, and anisometropia were not addressed.

This is the first population-based, national RE survey in Africa, to the authors' knowledge. The distribution of RE in

Table 5. Summary of Results from Selected Population-Based Refractive Error Studies

\begin{tabular}{|c|c|c|c|c|c|c|c|}
\hline Study & Country & $\begin{array}{l}\text { Sample } \\
\text { Size }\end{array}$ & $\begin{array}{c}\text { Age Group } \\
\text { (y) }\end{array}$ & Myopia & High Myopia & Hypermetropia & Astigmatism \\
\hline NBVIS & Pakistan $^{25}$ & 14,490 & $\geq 30$ & $<-0.5 \mathrm{G} ; 36.5$ & $<-5.0 \mathrm{D} ; 4.6$ & $>0.5 \mathrm{D} ; 27.1$ & $>0.75 \mathrm{D} ; 27.1$ \\
\hline NBLVS & Bangladesh $^{26}$ & 11,624 & $\geq 30$ & $\leq-0.5 \mathrm{D} ; 22.1$ & $\leq-5.0 \mathrm{D} ; 1.8$ & $>0.5 \mathrm{D} ; 20.6$ & $>0.5 \mathrm{D} ; 34.6$ \\
\hline APEDS & India $^{31}$ & 10,293 & $\geq 40$ & $<-0.5 \mathrm{D} ; 34.6$ & $<-5.0 \mathrm{D} ; 4.5$ & $>0.5 \mathrm{D} ; 18.4$ & $>0.5 \mathrm{D} ; 37.6$ \\
\hline MES & Myanmar $^{32}$ & 1,863 & $\geq 40$ & $<-1.0 \mathrm{D} ; 42.7$ & $<-6.0 \mathrm{D} ; 6.5$ & $>1.0 \mathrm{D} ; 15.0$ & $>1.0 \mathrm{D} ; 30.6$ \\
\hline SMES & Singapore $^{33}$ & 2,974 & $40-80$ & $<-0.5 \mathrm{D} ; 38.7$ & $<-5.0 \mathrm{D} ; 3.9$ & $>0.5 \mathrm{D} ; 27.4$ & $<-0.5 \mathrm{D} ; 33.3$ \\
\hline RES & Netherlands $^{34}$ & 6,543 & $\geq 55$ & $\leq 1.0 \mathrm{D} ; 17.6$ & $\leq-5.0 \mathrm{D} ; 4.0$ & $\geq 3.0 \mathrm{D} ; 17.6$ & Not studied \\
\hline \multirow[t]{3}{*}{ BES } & United States $^{35}$ & 5,036 & $\geq 40$ & $<-0.5 \mathrm{D} ; 19.4(\mathrm{~B})$ & $<-6.0 \mathrm{D} ; 0.0-1.4(\mathrm{~B})$ & $>0.5 \mathrm{D}$ & $>0.5 \mathrm{D}$ \\
\hline & & & & & & 41.0 (B) & $15.8-38.3(\mathrm{~B})$ \\
\hline & & & & $28.1(W)$ & $1.3-2.5(W)$ & $43.9(W)$ & $24.4-48.9$ (W) \\
\hline BDES & United States $^{36}$ & 4,533 & $43-84$ & $<-0.5 \mathrm{D} ; 26.2$ & $<-5.0 \mathrm{D} ; 3.8$ & $>0.5 \mathrm{D} ; 49$ & Not studied \\
\hline MVIP & Australia $^{37}$ & 4,744 & $\geq 40$ & $<-0.5 \mathrm{D} ; 17.0$ & $<-5.0 \mathrm{D} ; 2.1$ & $>0.5 \mathrm{D} ; 37.0$ & Not studied \\
\hline BMES & Australia ${ }^{38}$ & 3,654 & $49-97$ & $<-0.5 \mathrm{D} ; 15.0$ & $\leq-4.0 \mathrm{D} ; 3.0$ & $>0.5 \mathrm{D} ; 57.0$ & $>1.0 \mathrm{D} ; 37.0$ \\
\hline BdES & Barbados $^{39}$ & 4,709 & $\geq 40$ & $<-0.5 \mathrm{D} ; 21.9$ & Not studied & $>0.5 \mathrm{D} ; 46.9$ & Not studied \\
\hline
\end{tabular}

Data are expressed as the spherical equivalent in diopters and the prevalence (\%). NBVIS, National Blindness and Visual Impairment Survey; NBLVS, National Blindness and Low Vision Survey; APEDS, Andhra Pradesh Eye Disease Study; MES, Meiktila Eye Study; SMES, Singapore Malay Eye Survey; RES, Rotterdam Study; BES, Baltimore Eye Study; BDES, Beaver Dam Eye Study; MVIP, Melbourne Visual Impairment Project; BMES, Blue Mountains Eye Study; BdES, Barbados Eye Study; (B), black; (W), white participants. 
Nigeria appears closer to that of white and black populations in Europe and America, and differs from Asian populations. Findings indicate a low prevalence of myopia in Nigeria, exceedingly low spectacle coverage, a large unmet need for spectacles, and a need to improve the quality, access and affordability of optical and refractive services-a VISION2020 priority.

\section{Acknowledgments}

The authors thank Oye Quaye for managing the finances for the study; Auwal Shehu and Dania Charles for data entry; and the teams of ophthalmic nurses, enumerators, and interviewers in the six geopolitical zones who assisted in data collection.

\section{References}

1. Foster A, Resnikoff S. The impact of Vision 2020 on global blindness. Eye. 2005;19:1133-1135.

2. Resnikoff S, Pascolini D, Mariotti SP, Pokharel GP. Global magnitude of visual impairment caused by uncorrected refractive errors in 2004. Bull World Health Organ. 2008;86:63-70.

3. Lewallen S, Courtright P. Blindness in Africa: present situation and future needs. Br J Ophthalmol. 2001;85:897-903.

4. U.S. Census Bureau. International Data Base (IDB).Error! Hyperlink reference not valid.http://www.census.gov/cgi-bin/ipc/idbrank. pl. Accessed March 9, 2009.

5. Rabiu MM. Prevalence of blindness and low vision in north central, Nigeria. West Afr J Med. 2008;27:238-244.

6. Adeoti CO. Prevalence and causes of blindness in a tropical African population. West Afr J Med. 2004;23:249-252.

7. Fafowora OF. Prevalence of blindness in a rural ophthalmically underserved Nigerian community. West Afr J Med. 1996;15:228 231.

8. Abdu L. Prevalence and causes of blindness and low vision in Dambatta local government area, Kano State, Nigeria. Niger J Med. 2002;11:108-112.

9. Nwosu SN. Ocular problems of young adults in rural Nigeria. Int Ophthalmol. 1998;22:259-263.

10. Nwosu SN. Low vision in persons aged 50 and above in the onchocercal endemic communities of Anambra State, Nigeria. West Afr J Med. 2000;19:216-219.

11. Onakpoya OH, Adeoye AO, Akinsola FB, Adegbehingbe BO. Prevalence of blindness and visual impairment in Atakunmosa West Local Government area of southwestern Nigeria. Tanzan Health Res Bull. 2007;9:126-131.

12. Patrick-Ferife G, Ashaye AO, Qureshi BM. Blindness and low vision in adults in Ozoro, a rural community in Delta State, Nigeria. Niger J Med. 2005;14(4):390-395.

13. Okoye OI, Umeh RE. Eye health of industrial workers in Southeastern Nigeria. West Afr J Med. 2002;21:132-137.

14. Ashaye AO, Asuzu MC. Ocular findings seen among the staff of an institution in Lagos, Nigeria. West Afr J Med. 2005;24:96-99.

15. Scott SC, Ajaiyeoba AI. Eye diseases in general out-patient clinic in Ibadan. Niger J Med. 2003;12:76-80.

16. Nwosu SN. Blindness and visual impairment in Anambra State, Nigeria. Trop Geogr Med. 1994;46:346-349.

17. Umeh RE. The causes and profile of visual loss in an onchocerciasis-endemic forest-savanna zone in Nigeria. Ophthalmic Epidemiol. 1999;6:303-315.

18. Adeoti CO, Egbewale BE. Refractive errors in Mercyland Specialist Hospital, Osogbo, Western Nigeria. Niger Postgrad Med J. 2008; 15:116-119.

19. Adeoye AO, Omotoye OJ. Eye disease in Wesley Guild Hospital, Ilesa, Nigeria. Afr J Med Med Sci. 2007;36:377-380.

20. Bekibele CO, Fawole OI, Bamgboye AE, Adekunle LV, Ajayi R, Baiyeroju AM. Prevalence of refractive error and attitude to spectacle use among drivers of public institutions in Ibadan, Nigeria Ann Afr Med. 2007;6:26-30.

21. Hyman L. Myopic and hyperopic refractive error in adults: an overview. Ophthalmic Epidemiol. 2007;14:192-197.
22. Kyari F, Gudlavalleti MVS, Sivsubramaniam S, et al. Prevalence of blindness and visual impairment in Nigeria: The National Blindness and Visual Impairment Survey. Invest Ophthalmol Vis Sci. 2009; 50:2033-2039.

23. Abdull MM, Sivasubramaniam S, Murthy GV, et al. Causes of blindness and visual impairment in Nigeria: the Nigeria National Blindness and Visual Impairment Survey. Invest Ophthalmol Vis Sci. 2009;50:4114-4120

24. Dineen B, Gilbert CE, Rabiu M, et al. The Nigerian national blindness and visual impairment survey: rationale, objectives and detailed methodology. BMC Ophthalmol. 2008;8:17.

25. Shah SP, Jadoon MZ, Dineen B, et al. Refractive errors in the adult Pakistani population: the national blindness and visual impairment survey. Ophthalmic Epidemiol. 2008;15:183-190.

26. Bourne RR, Dineen BP, Ali SM, Noorul Huq DM, Johnson GJ. Prevalence of refractive error in Bangladeshi adults: results of the National Blindness and Low Vision Survey of Bangladesh. Ophthalmology. 2004;111:1150-1160.

27. Bourne RR, Dineen BP, Huq DM, Ali SM, Johnson GJ. Correction of refractive error in the adult population of Bangladesh: meeting the unmet need. Invest Ophthalmol Vis Sci. 2004;45:410417.

28. Rosser DA, Laidlaw DA, Murdoch IE. The development of a "reduced logMAR" visual acuity chart for use in routine clinical practice. BrJ Ophthalmol. 2001;85:432-436

29. Mehra V, Minassian DC. A rapid method of grading cataract in epidemiological studies and eye surveys. Br J Ophthalmol. 1988; 72:801-803.

30. WHO. WHO coding instructions for the WHO/PBL eye examination record (version III). Geneva: WHO; 1988: PBL/88.1.

31. Krishnaiah S, Srinivas M, Khanna RC, Rao GN. Prevalence and risk factors for refractive errors in the South Indian adult population: The Andhra Pradesh Eye disease study. Clin Ophthalmol. 2009;3: $17-27$.

32. Gupta A, Casson RJ, Newland HS, et al. Prevalence of refractive error in rural Myanmar: the Meiktila Eye Study. Ophthalmology. 2008; $115: 26-32$

33. Saw SM, Chan YH, Wong WL, et al. Prevalence and risk factors for refractive errors in the Singapore Malay Eye Survey. Ophthalmology. 2008;115:1713-1719.

34. Hofman A, Grobbee DE, de Jong PT, van den Ouweland FA Determinants of disease and disability in the elderly: the Rotterdam Elderly Study. Eur J Epidemiol. 1991;7:403-422.

35. Katz J, Tielsch JM, Sommer A. Prevalence and risk factors for refractive errors in an adult inner city population. Invest Ophthalmol Vis Sci. 1997;38:334-340.

36. Wang Q, Klein BE, Klein R, Moss SE. Refractive status in the Beaver Dam Eye Study. Invest Ophthalmol Vis Sci. 1994;35: $4344-4347$.

37. Wensor M, McCarty CA, Taylor HR. Prevalence and risk factors of myopia in Victoria, Australia. Arch Ophthalmol. 1999;117:658663.

38. Attebo K, Ivers RQ, Mitchell P. Refractive errors in an older population: the Blue Mountains Eye Study. Ophthalmology. 1999; 106:1066-1072.

39. Wu SY, Nemesure B, Leske MC. Refractive errors in a black adult population: the Barbados Eye Study. Invest Ophthalmol Vis Sci. 1999; 40:2179-2184

40. Young TL, Metlapally R, Shay AE. Complex trait genetics of refractive error. Arch Ophthalmol. 2007;125:38-48.

41. Dandona R, Dandona L, Naduvilath TJ, Srinivas M, McCarty CA, Rao GN. Refractive errors in an urban population in Southern India: the Andhra Pradesh Eye Disease Study. Invest Ophthalmol Vis Sci. 1999;40:2810-2818.

42. Lee KE, Klein BE, Klein R. Changes in refractive error over a 5-year interval in the Beaver Dam Eye Study. Invest Ophthalmol Vis Sci. 1999; 40:1645-1649.

43. Wu SY, Yoo YJ, Nemesure B, Hennis A, Leske MC. Nine-year refractive changes in the Barbados Eye Studies. Invest Ophthalmol Vis Sci. 2005;46:4032-4039.

44. Lee KE, Klein BE, Klein R, Wong TY. Changes in refraction over 10 years in an adult population: the Beaver Dam Eye study. Invest Ophthalmol Vis Sci. 2002;43:2566-2571. 
45. Guzowski M, Wang JJ, Rochtchina E, Rose KA, Mitchell P. Five-year refractive changes in an older population: the Blue Mountains Eye Study. Ophthalmology. 2003;110:1364-1370.

46. Hyams SW, Pokotilo E, Shkurko G. Prevalence of refractive errors in adults over 40: a survey of 8102 eyes. Br J Ophthalmol. 1977; 61:428-432.

47. Varma R, Wang MY, Ying-Lai M, Donofrio J, Azen SP. The prevalence and risk indicators of uncorrected refractive error and unmet refractive need in Latinos: the Los AngelesLatino Eye Study. Invest Opbthalmol Vis Sci. 2008;49:5264-5273.

48. Aine E. Refractive errors in a Finnish rural population. Acta Ophthalmol (Copenb). 1984;62:944-954.

49. Prema R, George R, Sathyamangalam Ve R, et al. Comparison of refractive errors and factors associated with spectacle use in a rural and urban South Indian population. Indian J Ophthalmol. 2008;56:139-144.

50. Mutti DO. Hereditary and environmental contributions to emmetropization and myopia. Optom Vis Sci. 2010;87:255-259.

51. Vitale S, Ellwein L, Cotch MF, Ferris FL 3rd, Sperduto R. Prevalence of refractive error in the United States 1999-2004. Arch Opbthalmol. 2008;126:1111-1119.

52. Lewallen S, Lowdon R, Courtright P, Mehl GL. A population-based survey of the prevalence of refractive error in Malawi. Opbthalmic Epidemiol. 1995;2:145-149.
53. Wong TY, Foster PJ, Hee J, et al. Prevalence and risk factors for refractive errors in adult Chinese in Singapore. Invest Ophthalmol Vis Sci. 2000;41:2486-2494.

54. Attebo K, Ivers RQ, Mitchell P. Refractive errors in an older population: the Blue Mountains Eye Study. Opbthalmology. 1999; 106:1066-1072.

55. Chew EY, Kimm J, Sperduto RD, et al. Evaluation of the age-related eye disease study clinical lens grading system AREDS report No. 31. Opbthalmology. 2010;117:2112-2119.

56. Thylefors B, Chylack LT, Konyama K, et al. A simplified cataract grading system The WHO Cataract Grading Group. Opbthalmic Epidemiol. 2002;9:83-95.

\section{Appendix}

\section{Additional Members of the Nigeria National Blindness and Visual Impairment Study Group}

Abdull Mahdi, Adenike Abiose, Olufunmilayo Bankole, Fatima Kyari, Hannah Faal, Abudallahi Imam, Pak Sang Lee, and Mansur Rabiu. 